\title{
Finite element modeling of the stability of rooms and resistance structures from the Cantacuzino Mine
}

\author{
Dacian-Paul Marian ${ }^{1 *}$, and Ilie Onica ${ }^{1}$ \\ ${ }^{1}$ University of Petroșani, Department of Mining Engineering, Surveying and Civil Engineering, \\ University st., no. 20, Petroșani, Romania
}

\begin{abstract}
The Cantacuzino Mine was mined with small rooms and square pillars, on seven levels, over a period of 27 years, extracting over 2.3 million $\mathrm{m}^{3}$ of rock salt. Due to the specific geo-mining conditions, the support structures suffered different degrees of deformation, especially the cracking of the ceilings between the first 5 levels. This article presents a 3D finite element analysis, in elasto-plasticity, of the state of stress and strain that generated the deformation of the pillars and ceilings between levels.
\end{abstract}

\section{Generalities}

The underground mining of the rock salt deposit from Slănic began between 1665-1865 with the help of bell shape type rooms and continued with the exploitation in large trapezoidal rooms in the Old Mines (Sistematica 1865-1875; Principatele Unite or Carol Mine, between 1831-1935; 23 August or Mihai Mine, between 1912-1943; Unirea Mine, in the period 19471971), from where a volume of over 5.5 million $\mathrm{m}^{3}$ of rock salt was extracted.

In 1970, the Victoria Mine was opened, where the mining method with small rooms and square pillars, with multi-storey levels, was applied, with which a volume of 7,379,128 $\mathrm{m}^{3}$ was extracted from the deposit.

In 1993, the activity continued at the Slănic Prahova salt mine by opening the Cantacuzino mine, where the mining method with small rooms, square pillars and a straight ceiling, was applied, between the levels V and VII, and starting from level VIII, the same method was applied, but with rooms with vaulted ceilings. The sizes of the pillars increased with the depth, as follows: for levels V - VII, $L_{p}=16 \mathrm{~m}$; for levels VIII - X, $L_{p}=17 \mathrm{~m}$; for the XI level, $L_{p}=18 \mathrm{~m}$.

Until 2019, approx. 4,964,880 tonns of rock salt and a total volume of approx. $2,364,229 \mathrm{~m}^{3}$ (Table 1). The depth on which the underground mining voids have developed is $103 \mathrm{~m}$, under a massif of rock salt and covering rocks, ranging between $102 \mathrm{~m}$ and $160 \mathrm{~m}$ (depending on the relief of the surface). Taking into account these general data, it can be noted that, from the stability point of view, the geo-mining conditions of the Cantacuzino mine are much more favorable, compared to those specific to the Victoria Mine and the Old Mines.

\footnotetext{
* Corresponding author: dacianmarian@upet.ro
} 
As the exploitable reserves at the Cantacuzino Mine, located above the $+200 \mathrm{~m}$ level, have been depleted, currently the activity continues below the level +200 , starting with the $14^{\text {th }}$ level, located under an crown pillar, with an average thickness of $40 \mathrm{~m}$.

Table 1. Evolution of the volume of annual excavations at the Cantacuzino Mine, in the period 1990-2019 [1].

\begin{tabular}{|c|c|c|c|c|c|}
\hline Year & Volume, $\left.\mathbf{( m}^{\mathbf{3}}\right)$ & Year & Volume, $\left.\mathbf{( m}^{\mathbf{3}}\right)$ & Year & Volume, $\left(\mathbf{m}^{\mathbf{3}}\right)$ \\
\hline 1990 & 1,247 & 2000 & 90,004 & 2010 & 57,932 \\
\hline 1991 & 11,488 & 2001 & 76,417 & 2011 & 56,690 \\
\hline 1992 & 39,952 & 2002 & 75,478 & 2012 & 65,064 \\
\hline 1993 & 144,429 & 2003 & 93,861 & 2013 & 62,686 \\
\hline 1994 & 134,763 & 2004 & 79,670 & 2014 & 54,847 \\
\hline 1995 & 146,001 & 2005 & 81,755 & 2015 & 52,980 \\
\hline 1996 & 151,456 & 2006 & 74,918 & 2016 & 41,442 \\
\hline 1997 & 159,226 & 2007 & 51,668 & 2017 & 65,599 \\
\hline 1998 & 137,151 & 2008 & 46,250 & 2018 & 84,154 \\
\hline 1999 & 100,602 & 2009 & 50,213 & 2019 & 76,285 \\
\hline \multicolumn{7}{|c|}{ TOTAL 1990-2019 } & $\mathbf{2 , 3 6 4 , 2 2 9}$ \\
\hline
\end{tabular}

\section{The 2D and 3D finite elements models for the Cantacuzino Mine - Slănic Saline}

In order to analyze the overall stability of the Cantacuzino Mine, two numerical models with finite elements were built, namely: one in 3D (Figure 1.a and b) and another in 2D - plane strain (Figure 1.c).
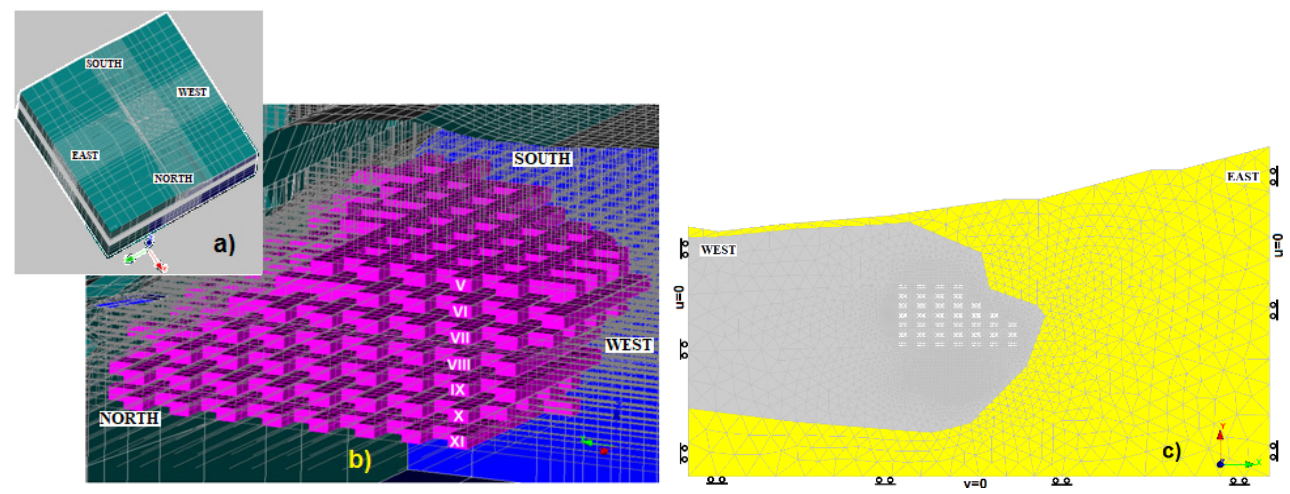

Fig. 1. Discretization with finite elements of the model related to the Cantacuzino Mine [1]: a) The 3D model as a whole; b) View of the 3D model from the N-W with the rooms and pillars from the V-XI levels; c) The 2D finite element model.

The 2D finite element model, for the Cantacuzino Mine, has the sizes of $X=995 \mathrm{~m}$ and $\mathrm{Y}=545 \mathrm{~m}$, and the 3D model has the sizes of $\mathrm{X}=1,088 \mathrm{~m}, \mathrm{Y}=1,088 \mathrm{~m}$ and $\mathrm{Z}=473 \mathrm{~m}$.

The discretization of the 2D model, respectively of each region was achieved by 9,469 finite elements of triangular surface with square interpolation, respectively 20,903 nodes. Regarding the discretization of the 3D model, from the Cantacuzino Mine, the elements of discretization of the model are as follows: the total number of nodes is of 68,640 ; total number of volume elements is of 63,338 . 
To simplify the 2D and 3D numerical models, two regions with specific geomechanical characteristics were considered, corresponding to the surrounding rocks and the rock salt deposit [2-6]. The characteristics of the rock salt (mainly), considered homogeneous and isotropic, were taken into account in the hypothesis of elastic-plastic behavior without hardening, Mohr-Coulomb type. Thus, a series of average characteristics were adopted, considered by us as representative for the in-situ behavior of the rock salt massif and of the surrounding rocks and synthesized in Table 2.

Table 2. The main average geo-mechanical characteristics of the rock salt massif and surrounding rocks taken into account in the finite element modeling [1].

\begin{tabular}{|l|l|c|c|}
\hline \multirow{2}{*}{ Properties } & \multirow{2}{*}{$\begin{array}{c}\text { Measurement } \\
\text { unit }\end{array}$} & \multicolumn{2}{c|}{ Value } \\
\cline { 2 - 4 } & \multicolumn{2}{|c|}{ Rock salt } & Surrounding rocks \\
\hline \multirow{2}{*}{ Density, $\rho_{a}$} & $\mathrm{~kg} / \mathrm{m}^{3}$ & 2,100 & 2,200 \\
\hline \multirow{2}{*}{ Apparent specific weight, $\gamma_{a}$} & $\mathrm{kN} / \mathrm{m}^{3}$ & 21 & 22.0 \\
\cline { 2 - 4 } & $\mathrm{MN} / \mathrm{m}^{3}$ & 0.021 & 0.022 \\
\hline \multirow{2}{*}{ Young modulus of elasticity, $E$} & $\mathrm{kN} / \mathrm{m}^{2}$ & $2,500,000$ & $3,000,000$ \\
\cline { 2 - 4 } & $\mathrm{MPa}$ & 2,500 & 3,000 \\
\hline Poisson ratio, $\boldsymbol{V}$ & & 0.28 & 0.21 \\
\hline \multirow{2}{*}{ Compressive strength, $\sigma_{c}$} & $\mathrm{kN} / \mathrm{m}^{2}$ & 20,000 & - \\
\cline { 2 - 4 } & $\mathrm{MPa}$ & 20 & - \\
\hline \multirow{2}{*}{ Tensile strength, $\sigma_{t}$} & $\mathrm{kN} / \mathrm{m}^{2}$ & 1,400 & - \\
\cline { 2 - 4 } & $\mathrm{MPa}$ & 1.4 & - \\
\hline \multirow{2}{*}{ Shear strength, $\tau_{f}$} & $\mathrm{kN} / \mathrm{m}^{2}$ & 2,300 & - \\
\cline { 2 - 4 } & $\mathrm{MPa}$ & 2.3 & - \\
\hline \multirow{2}{*}{ Cohesion, $C$} & $\mathrm{kN} / \mathrm{m}^{2}$ & 4,000 & 5,300 \\
\cline { 2 - 4 } & $\mathrm{MPa}$ & 30 & 5.3 \\
\hline Internal friction angle, $\varphi$ & $\mathrm{o}$ & & 24 \\
\hline
\end{tabular}

In the analysis of the stability of the excavations and underground mining structures and of the surface from the Cantacuzino Mine - Slănic Prahova Saline, CESAR-LCPC finite element software with CLEO2D and CLEO3D processors was used [7].

Carrying out the analysis with finite elements in $2 \mathrm{D}$, in plane strain, and $3 \mathrm{D}$, for the models defined above, required the following steps: I) establishing the limits, the area of interest and discretizing the model; II) determination of areas (regions), calculation hypotheses and introduction of geomechanical characteristics; III) imposing boundary conditions; IV) establishing the initial and loading conditions of the model; V) performing calculations and storing the results [7].

From the beginning we notice that both the Cantacuzino Mine and the Victoria Mine are the result of applying the underground mining method with small rooms and square pillars. Therefore, the geomechanical phenomena that have affected over time the resistance structures in these two mines are similar, with certain differences dictated by the geomining peculiarities of each mine [3].

Taking into account the advantages and disadvantages offered by the two types of models with finite elements (2D and 3D), below, a stability analysis of the Cantacuzino Mine will be performed, taking into account the most representative results, from a qualitative and quantitatively point of view and which may justify the geomechanical phenomena of instability that occurred at this mine [8-10].

Although the 2D model is based on a series of simplifying assumptions, it allowed for a denser discretization of the model. This made certain results much more detailed, compared 
to those obtained from the 3D model for which, due to the large size of the model, to make it feasible, a wider discretization with volume finite elements was needed. The advantage of the 3D model is given by the fact that the results obtained from the calculations are expressed along the 3 coordinate axes, $x, y$ and $z$ (respectively according to the EV, NS and up-down orientations), while those provided by the 2D modeling are only after two axes (respectively EV and up-down). Also, in this stability analysis the interest was focused, especially, on the last three levels (IX, X and XI), which directly influence the existing functional area in the rooms located on the $\mathrm{X}^{\text {th }}$ level, because the finite element model in 3D it is very extensive and very difficult to study in detail.

\section{Analysis of the results obtained from the finite element numerical modeling of the Cantacuzino Mine}

In order to explain the geomechanical phenomena of loss of stability of the resistance structures appeared at the Cantacuzino Mine, the stress concentration ratios according to the coordinate directions and the maximum / minimum principal stresses can describe the stress imbalance and implicitly the possibility of failure phenomena [11]. A ratio as high as possible makes the circle of the principal stresses intersect the characteristic curve of the rocks, which has as a significance the development of some failure phenomena or the opening of some fissures or natural fractures in the massif. Also, from the stability point of view, the study of tensile and shear stresses is very significant, knowing that the rock salt has very low tensile and shear strengths and most often the failure occurs due to the exceeding of these limits. The analysis of the values of vertical and horizontal displacements and of the orientation of their corresponding vectors can suggest the amplitude and the sense of development of the deformation phenomena [12].

The vertical displacements $v-2 \mathrm{D}$ (Figure 2.a) and $w$-3D (Figure 2.b) are generally subsidence, for the structures from the upper levels V-VIII and ascending vertical displacements, for the levels IX-XI. The vertical displacements of the underground resistance structures were transmitted to the surface, through the safety crown pillar and the waste covering rocks, generating maximum subsidence of approx. $60 \mathrm{~mm}$, obtained from calculations performed on the 3D model. The distribution of vertical displacements on the surface of the levels is different: if to the west there are pronounced liftings of the floor of the rooms on the level IX, they attenuate, turning into minor subsidence at the eastern limit of the mining field. In the case of levels X and XI, all the floors are driven in ascending / lifting movements, accentuated towards the western limit of the mining field. These phenomena are highlighted by the leveling topographic measurements performed on the landmarks mounted on the floors between the levels [12].

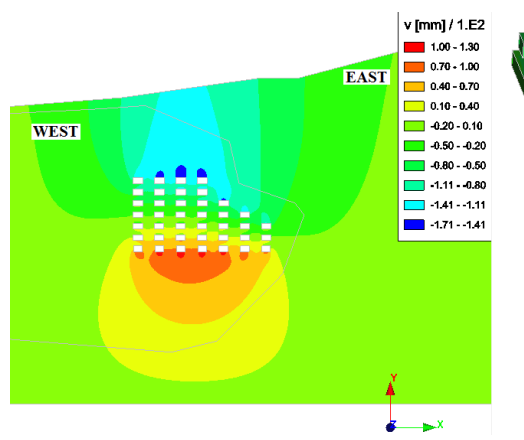

a)

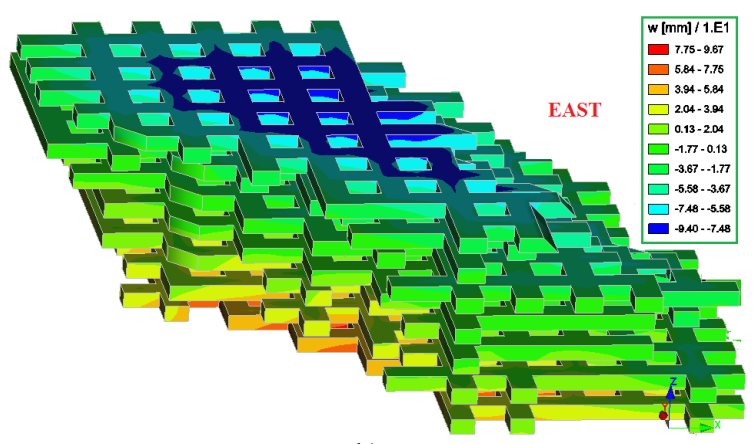

b)

Fig. 2. Vertical displacements, in mm - scalar representation [1]: a) v-2D; b) w-3D. 
Horizontal displacements $u-2 \mathrm{D}$ and $u, v-3 \mathrm{D}$. The horizontal displacements $u$ are greater towards the western limit of the deposit, increasing in value with the increase in depth of the mining excavations. The horizontal displacements $v-3 \mathrm{D}$ are amplified towards the southwestern direction and with the transition from the level IX to level XI. Analyzing the horizontal displacements $u$-3D and $v$-3D (Figure 3), from the level of the interdiction zone/pillar established at the level IX, we can see a balance of the horizontal displacements, due to the increased rigidity of the massif in this area, which demonstrates the fact that this pillar has an obvious self-supporting character and does not complicate the structure of the $\mathrm{X}^{-{ }^{\text {th }}}$ level.

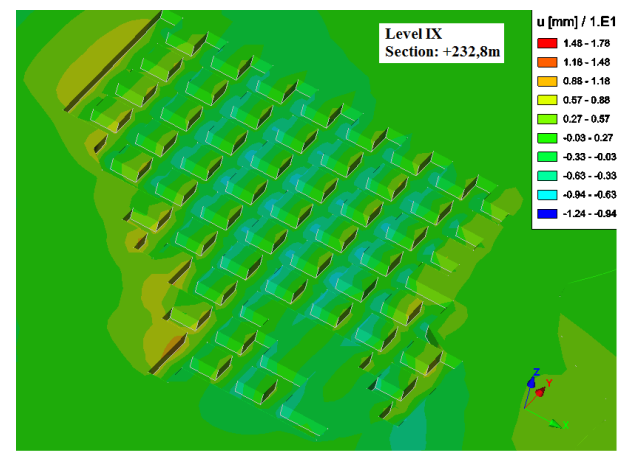

a)

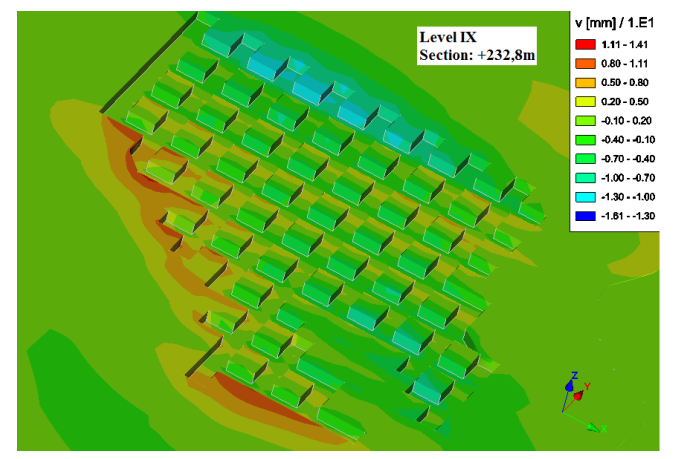

b)

Fig. 3. Horizontal displacements, in mm - view level IX (+225m): [1]: a) $u$-3D; b) $v-3 \mathrm{D}$. Model orientations: $+x$ east; $-x$ west; $+y$ north; $-y$ south; $+z$ vertical up; $-z$ vertical down

Vertical stresses $\sigma_{y y}-2 \mathrm{D}$ (Figure 4.a) and $\sigma_{z z}-3 \mathrm{D}$ (Figure 4.b and c). These stresses show the redistribution of the initial geostatic stresses around the underground mining excavations, respectively on the edges of the mining field and the mining pillars. Vertical stresses mostly involve the intercameral pillars, with an average increase starting from approx. $-12,000 \mathrm{kN} / \mathrm{m}^{2}$, for level $\mathrm{V}$, at approx. $-16,000 \mathrm{kN} / \mathrm{m}^{2}$, in the levels X-XI. There is also an increase in stresses towards the walls by over $20 \div 30 \%$, the most affected pillars being those from the levels $\mathrm{X}$ and XI, where the vertical stresses on the walls can exceed $20,000 \mathrm{kN} / \mathrm{m}^{2}$. In general, there is a significant increase in vertical stresses on the pillars from levels X and XI and on the first three columns of the pillars from the east of the mining field.

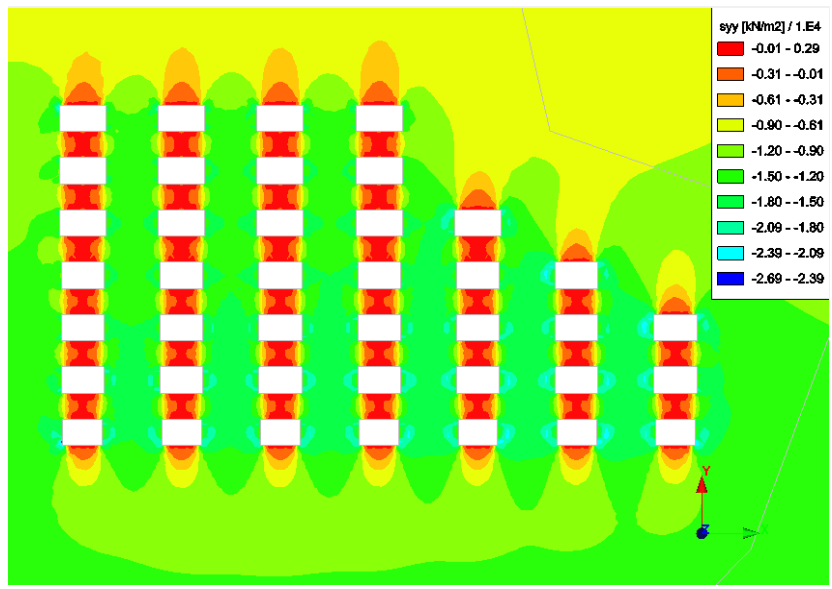

a) 


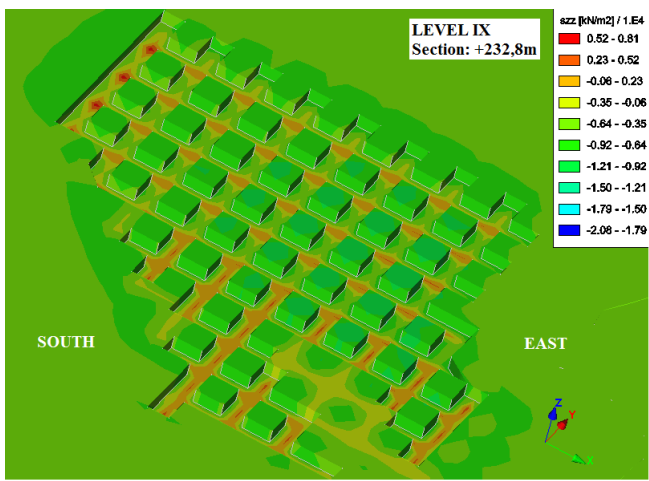

b)

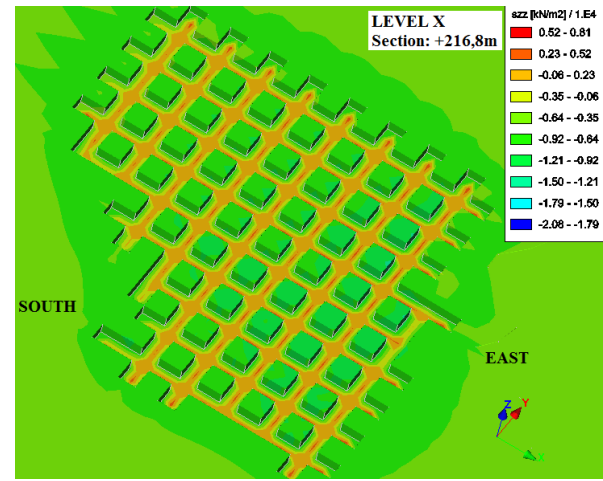

c)

Fig. 4. Vertical stresses, in $\mathrm{kN} / \mathrm{m}^{2}$ [1]: a) $\sigma_{y y}$ - for 2D; b) $\sigma_{z z}-3 \mathrm{D}$ - view level IX $(+225 \mathrm{~m})$; c) $\sigma_{z z}$ for 3D - view level X ( $+209 \mathrm{~m})$. Model orientations: $+x$ east; $-x$ west; $+y$ north; $-y$ south; $+z$ vertical up; $-z$ vertical down.

The horizontal stresses $\sigma_{x x}-2 \mathrm{D}$ after E-W (Figure 5.a) and $\sigma_{x x}-3 \mathrm{D}$ after E-W (Figure 5.b), $\sigma_{y y}-3 \mathrm{D}$ after N-S (Figure 5.c), are redistributed mainly on the ceilings of all levels and on the marginal safety pillars at the base of the mine and on the roof.

After the W-E direction, there is an increase of the stresses, from approx. $-5,000 \mathrm{kN} / \mathrm{m}^{2}$, in the ceiling between the level V and VI, up to approx. $-7,000 \mathrm{kN} / \mathrm{m}^{2}$, in the ceilings above the last three levels, with an accentuation towards the eastern limit. There is the appearance of tensile zones, with a similar distribution, in the middle of the rooms oriented E-W. After the N-S direction, the stresses $\sigma_{y y}$ are distributed somewhat similarly at the level of the rooms oriented N-S, respectively in the ceiling between levels X and XI. Instead, the presence of the interdiction pillar on level IX causes the distribution of stresses $\sigma_{y y}$ to affect the rooms around this pillar. It should also be noted that for the last room on the west side of the ninth level, the ceiling is affected by tensile stresses, concentrated at its intersection with the rooms in the E-W direction. The peculiarity of this room, located at the western limit of the mining field, is that it is a room bordered by a continuous wall, compared to other discontinuous boundaries, marked by alternating pillars and with less stressed ceilings. Therefore, in order to increase the stability of the ceilings located in these particular conditions, it is recommended that the wall of the level located towards the operating edges, as far as possible, not be a continuous one.

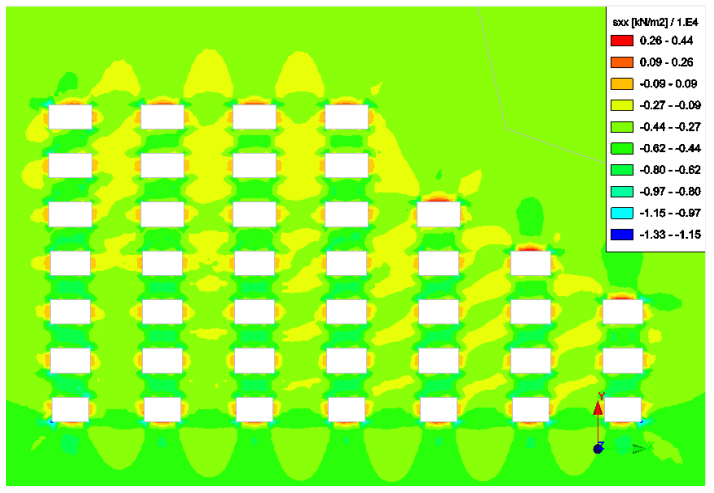

a) 


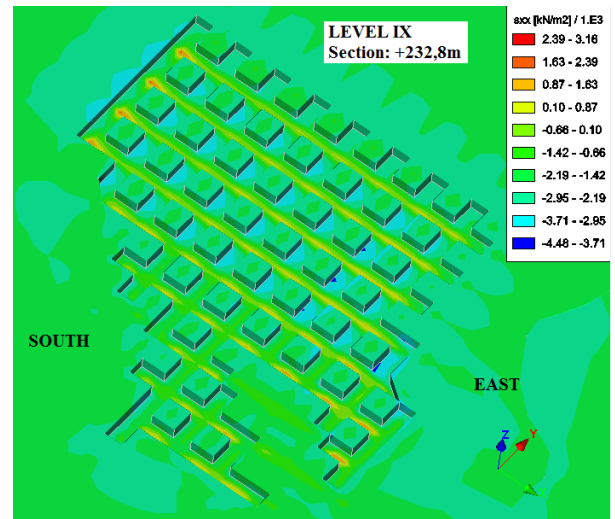

b)

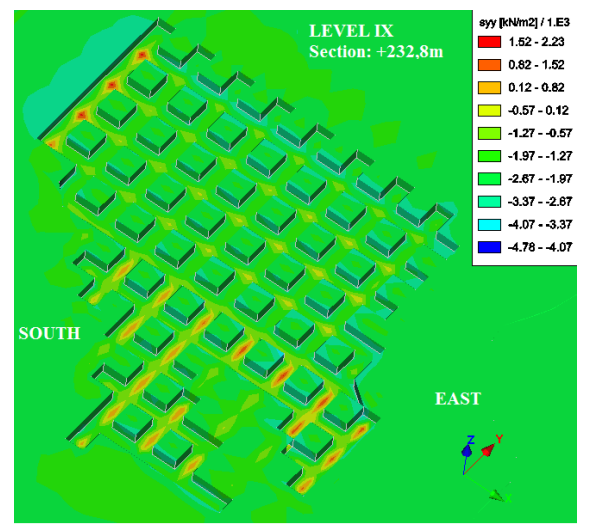

c)

Fig. 5. Horizontal stresses, in $\mathrm{kN} / \mathrm{m}^{2}-$ view level IX (+225m) - [1]: a) $\sigma_{x x}$ - for 2D; b) $\sigma_{x x}$ - for 3D; c) $\sigma_{y y}$ - for $3 \mathrm{D}$.

The maximum (major) principal stresses $\sigma_{1}-2 \mathrm{D}$ (Figure 6.a) and $\sigma_{1}-3 \mathrm{D}$ (Figure 7.a) and minimum (minor) principal stresses $\sigma_{2}-2 \mathrm{D}$ (Figure 6.b) or $\sigma_{3}-3 \mathrm{D}$ (Figure 7.b) are the most representative stresses for a stability analysis, their ratio highlighting the degree of balance of the material points in the analyzed massif.

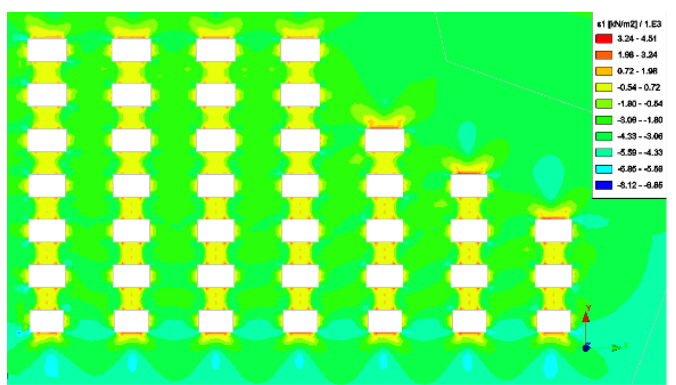

b)

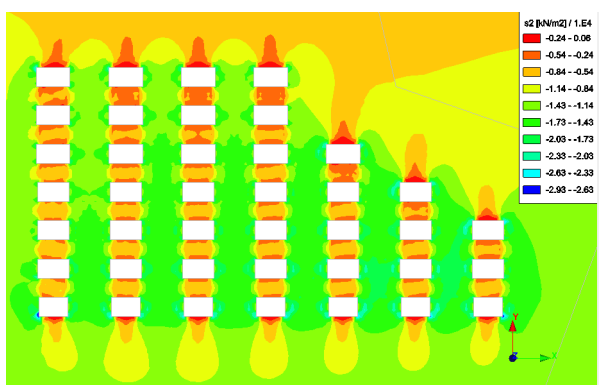

c)

Fig. 6. The principal stresses $2 \mathrm{D}$, in $\mathrm{kN} / \mathrm{m}^{2}$ - scalar representation [1]): a) maximum $\sigma_{1}-2 \mathrm{D}$;

b) minimum $\sigma_{2}-2 \mathrm{D}$.

The major principal stresses developed in the resistance structures are, in general, compressive stresses (developed in the intercameral and marginal pillars) and tensile stresses, in the ceilings and in the walls of the rooms. In pillars, the principal major/maximum stresses vary from approx. $-3,000 \mathrm{kN} / \mathrm{m}^{2}$, on the first level, up to approx. $-5,000 \mathrm{kN} / \mathrm{m}^{2}$, on the last level, with a slight increase to the east of the deposit. In general, in all the ceilings between the levels and in the walls of the rooms, the principal major stresses are tensile stresses, with values between $+350 \mathrm{kN} / \mathrm{m}^{2}$ and $+650 \mathrm{kN} / \mathrm{m}^{2}$. There are two local areas in the ceiling and the floor of the rooms affected by tensile stresses, which have values that can exceed more than twice the value of tensile strength of the rock salt, and where can appear detachments/cracks from the ceiling and opening/forming of some fractures and/or the mobilization of some natural fissures in the floor of the rooms. The most affected by the maximum principal stresses are the ceilings of the first row of rooms, below the marginal safety pillar, where the principal major stresses can exceed three times the value of tensile strength of the rock salt, in the floor of the rooms on the level XI and in the ceiling between levels IX and X, from the western boundary of the mining field. 
All minor principal stresses in the analyzed models are compressive stresses with values ranging between $-12,000 \mathrm{kN} / \mathrm{m}^{2}$ and $-15,000 \mathrm{kN} / \mathrm{m}^{2}$, for pillars, between the first and the last level and between $-4,000 \mathrm{kN} / \mathrm{m}^{2}$ and $-7,000 \mathrm{kN} / \mathrm{m}^{2}$, for all ceilings between the levels. Here, too, there is an increase in compressive stresses towards the base of the pillars on the last two levels, at values that exceed the compressive strength of the rock salt and which may explain the destruction of the corners and outer surfaces of the pillars, starting from the limit with the floor of the rooms. Also, from the point of view of the minimum principal stresses, there can be a de-tensioning of the ceilings in their middle, which corroborated with the increase of the maximum principal stresses, show that favorable local conditions can be created for the degradation of the ceilings in these areas.

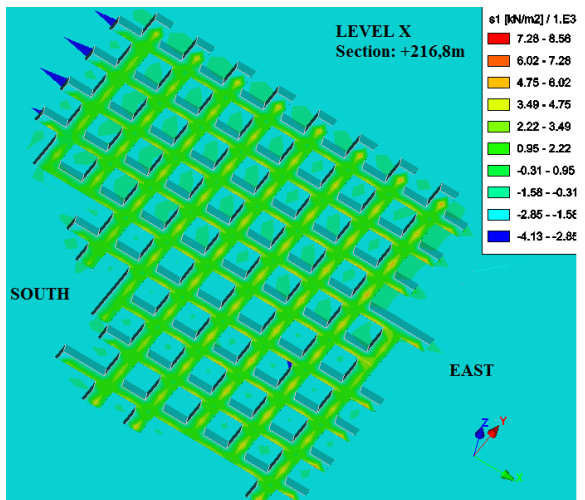

b)

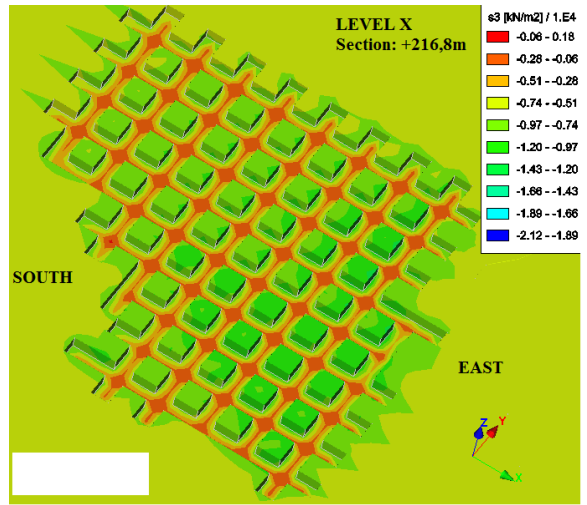

c)

Fig. 7. The principal stresses $3 \mathrm{D}$, in $\mathrm{kN} / \mathrm{m}^{2}$-view level $\mathrm{X}(+209 \mathrm{~m})$ [1]: a) maximum $\sigma_{1}-3 \mathrm{D}$; b) minimum $\sigma_{3}-3 \mathrm{D}$.

The maximum shear stresses $\tau_{f \text { max }}$ (Figure 8) indicate the structural areas where there is the potential for the occurrence of shear fractures of the rock salt massif or the mobilization of natural fissures or fractures existing into the massif. Because the value of the shear strength of the rock salt is quite low, of approx. $2,300 \mathrm{kN} / \mathrm{m}^{2}$, the maximum shear stresses $\tau_{f \text { max }}$, together with the tensile stresses, can be the cause of most of the phenomena of degradation of the resistance structures (pillars, rooms) and of the appearance of underground collapses.

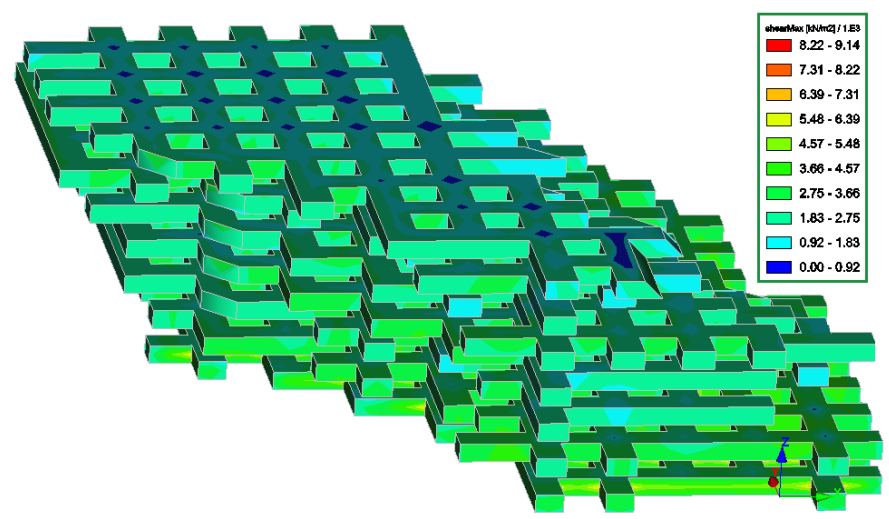

Fig. 8. Maximum shear stresses, $\tau_{f \max }$ in $\mathrm{kN} / \mathrm{m}^{2}$ - overview of the Cantacuzino mine [1]. 
Tensile stresses $\sigma_{t}$ (Figure 9.a) primarily affects the floors, in two areas of the ceiling and certain local areas at the walls. The marked areas in the ceiling of the rooms are prone to rock salt detachment and the formation of two collapse vaults, and in the floor of the rooms cracks may occur or families of pre-existing fissures/fractures may open. In the walls of the rooms, especially at the corners of the pillars, their failures can occur, leading, in time, to the decrease of the load-bearing capacity of the pillars. If the tensile stresses on the walls of the rooms vary between $+1,000 \div+1,200 \mathrm{kN} / \mathrm{m}^{2}$, at the limit of the tensile strength of the rock salt, on the ceiling and floor, most of the stresses are between $+3,000 \mathrm{kN} / \mathrm{m}^{2}$ and $+3,500$ $\mathrm{kN} / \mathrm{m}^{2}$, which obviously shows the occurrence of some failure phenomena caused by tensile stresses in these areas marked by instability.

If in the case of the other analyzed levels a certain uniform distribution in the ceilings of the traction stresses is found, if the level IX is analyzed (Figure 9.b) a concentration of the traction stresses can be noticed around the interdiction pillar and an alignment of the traction stresses in the rooms arranged in the E-W direction. Also, on this level there is a maximum concentration of tensile stresses in the western room, from the boundary with the marginal pillar, which proves once again that at the contact with the contour of the mining field must be placed intermittent pillars to increase the stability of the structures in these areas.

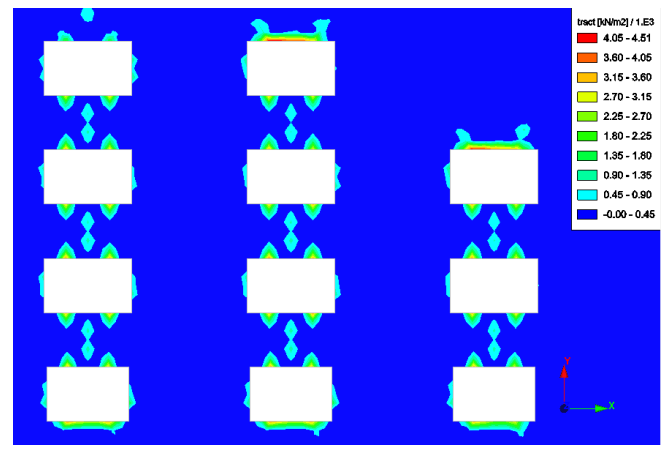

a)

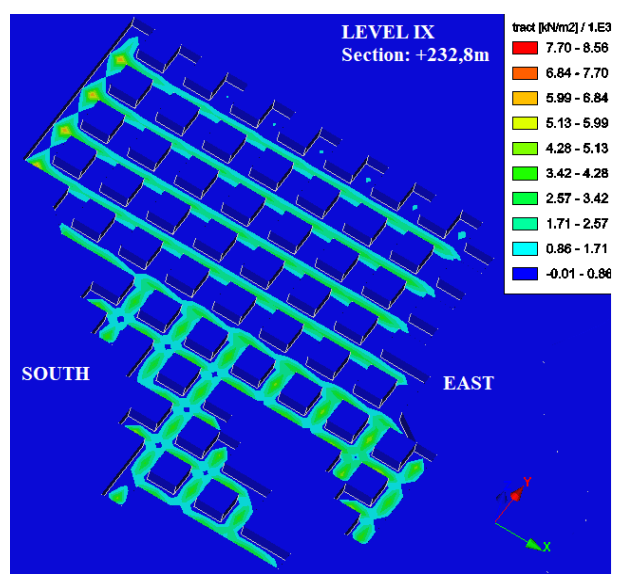

b)

Fig. 9. Tensile stresses, in $\mathrm{kN} / \mathrm{m}^{2}$ - scalar representation [1]: a) $\sigma_{t}-2 \mathrm{D}$; b) $\sigma_{t}-3 \mathrm{D}$, view level IX (+ $225 \mathrm{~m})$

Compressive stresses $\sigma_{c}$ (Figure 10.a) mainly affects the intercameral pillars, increasing from average values of $-12,000 \div-13,000 \mathrm{kN} / \mathrm{m}^{2}$, at level $\mathrm{V}$, to $-15,000 \mathrm{kN} / \mathrm{m}^{2}$ $\div-17,000 \mathrm{kN} / \mathrm{m}^{2}$, on the XI-th level. There is a concentration of compressive stresses in the pillars at the boundary with the ceilings, until the value of compressive strength is reached, of $-20,000 \mathrm{kN} / \mathrm{m}^{2}$. It is also observed a higher stress of the pillars below the eastern marginal pillar and of the pillars on the levels $X$ and XI, up to a value of $-25,000 \mathrm{kN} / \mathrm{m}^{2}$.

In ceilings, the stresses do not exceed the value of approx. $-6,000 \div-8,000 \mathrm{kN} / \mathrm{m}^{2}$ at level X, which makes them stable in terms of compressive stresses.

On level IX, redistributions of compressive stresses are observed in all resistance structures, generated by the presence of the interdiction pillar at the southeastern limit of the mining field (figure 10.b). 


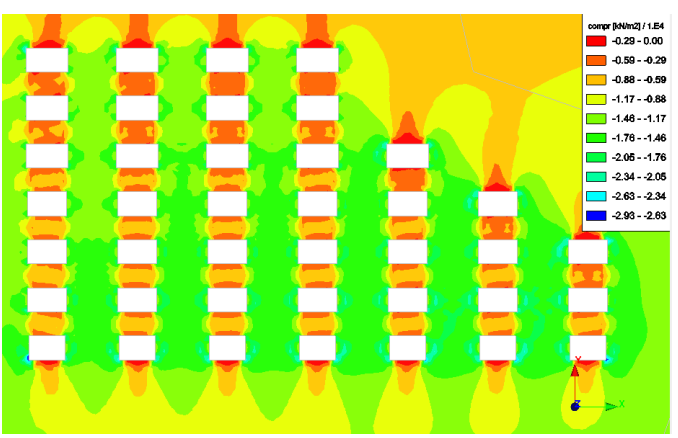

a)

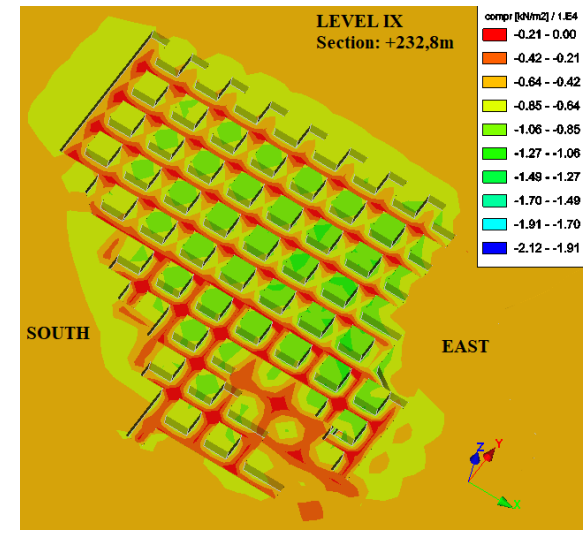

b)

Fig. 10. Compressive stresses, in $\mathrm{kN} / \mathrm{m}^{2}$ [1]: a) $\sigma_{c}-2 \mathrm{D}$; b) $\sigma_{c}-3 \mathrm{D}$, view level IX $(+225 \mathrm{~m})$.

The plastic deformation norm NDP (Figure 11) indicates the local areas in the resistance structures of the Cantacuzino Mine in a state of plastic deformation. We note that, in the case of the Cantacuzino Mine, there are no areas of plastic deformation in the ceilings, but only in the walls of the rooms, respectively at the corners of the pillars. The most affected by the plastic deformation are levels XI and X and the rooms under the eastern marginal pillar, from levels VII, VIII and IX.

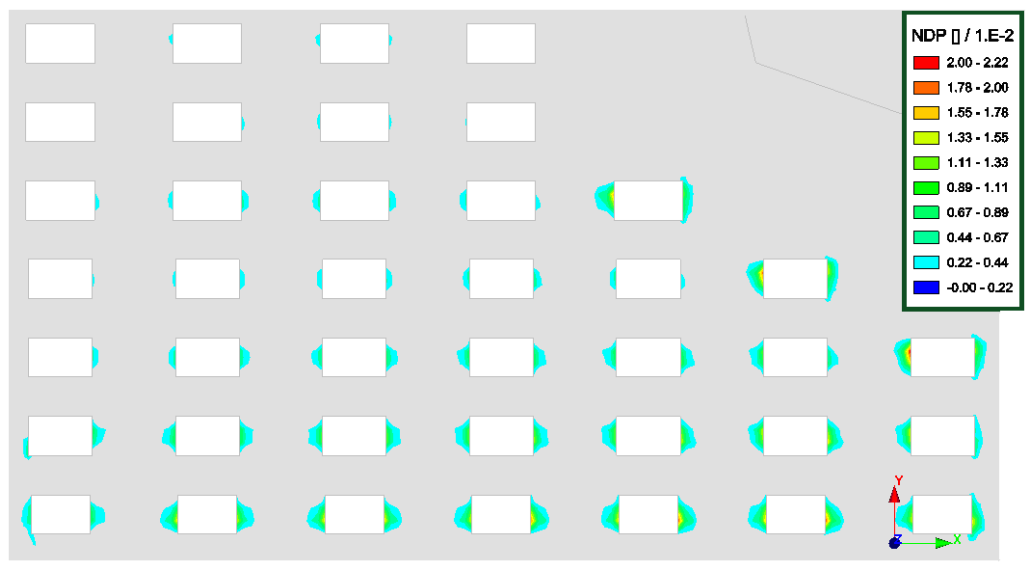

Fig. 11. The plastic deformation norm NDP [1].

Following the analysis of the stress-strain state of the resistance structures from the Cantacuzino Mine, resulted from the numerical models with finite elements in 2D and 3D, it can be concluded that the overall stability of the pillars and ceilings is relatively good, and acceptable at the last three levels, which makes these levels functional for a limited time.

\section{Conclusions}

The Cantacuzino Mine was exploited with small rooms and square pillars, extracting over 2.3 million $\mathrm{m}^{3}$ of rock salt, which led to an increased instability of the resistance structures, especially the cracking of the ceilings from the first 5 levels. 
In order to establish the causes that led to the instability of the resistance structures from this mine, a modeling with finite elements in $2 \mathrm{D}$ and $3 \mathrm{D}$, in elasto-plasticity, was performed with the aid of the CESAR-LCPC software.

The state of stresses and strains of the entire model was analyzed, with the focus of interest on the last three levels. In the analysis, both vertical and horizontal displacements were taken into account.

Also, in the stability analysis of the resistance structures, the distribution of stresses along the three axes, the distribution of principal stresses, maximum shear, tensile and compressive stresses, compared to the strength of the rock salt massif, were taken into account.

In areas where the stresses in the resistance structures exceeded the specific strengths of the rock salt, it was assumed that a series of phenomena of loss of stability occurred, with varying degrees of intensity, such as fractures in certain areas of the ceilings and the breaking of the corners of the pillars.

\section{References}

1. D.P. Marian, I. Onica, M. Georgescu, E. Cozma, et.al., Study on the stability of constructions and surface in the perimeter of influence of Old Mines (Ocna din Deal and Ocna din Vale), Victoria, Unirea and Cantacuzino according to know existing data (topographic, rheological, geological, hydrogeological, etc.) as well as the deformations of the resistance elements of the underground excavations in the Cantacuzino mine, in order to carry out in safe conditions the underground mining activity and protection of the civil and industrial (University of Petrosani, Research Contract no. 186/15.10.2019) - (in Romanian)

2. C. Hirian, Rock mechanics (Didactic and Pedagogic Publishing House, Bucharest, 1981) - (in Romanian)

3. C. Hirian, M. Georgescu, Stability of the old Salt Mines from Romania-condition of their use for various fields (Universitas Publishing House, Edition a II-a, 2012) - (in Romanian)

4. M. Milea, et. al., Study of the physical-mechanical and rheological parameters of the rock salt from the Slănic Prahova deposit and resizing the elements of the resistance structures (pillarsceilings) of the extracted areas (Cantacuzino mine), in order to ensure the overall stability of the area, Stage II / Part 1 - Statistical processing of the data resulting from laboratory tests (SC MINESA-ICPM SA Cluj-Napoca, Research Contract no. 10 848/2011/26.10.2007; Symbol project 49-724-01, 2009) - (in Romanian)

5. M. Stamatiu, The problem of pillars design at rock salt mines in Romania (Publishing House of the Academy, 1959) - (in Romanian)

6. M. Stamatiu, Rock mechanics (Didactic and Pedagogical Publishing House, Bucharest, 1962) - (in Romanian)

7. I. Onica, D.P. Marian, Applications of the finite element method in the analysis of surface stability and underground structures (Universitas Publishing House, Petrosani, 2016) - (in Romanian)

8. S. Berchimis et. al., Identification of fractures and fissures in the Cantacuzino and Unirea Mine by geophysical methods; Stage I-Cantacuzino Mine, Levels VIII, IX, X (SC IPROMIN SA, Research Contract no. 16079/2004) - (in Romanian)

9. I. Oancea, et. al., Monitoring the mining subsidence in salt mines by geophysical tomography methods in order to avoid collapse phenomena. Phase II: Investigation by methods of geophysical tomography of pillars and ceilings - Phase I (Abstract) (INCDMRR Bucharest, 2006) - (in Romanian).

10. I. Oancea, et. al., Electrometric measurements and geophysical study for the investigation of structural weakening areas in levels VIII, $I X$ and $X$ of the Cantacuzino mine (SC IPROMIN SA, Research Contract 1946/22.03.2007) - (in Romanian)

11. G. Herget, Stresses in rock (Balkema, 1988)

12. D.P. Marian, I. Onica, B. Postolachi, Analysis of the main factors that led to deformation and cracking of the ceilings between the mining levels of Cantacuzino Mine - Slănic Saline, Revista minelor, Vol. 26, nr. 3, pp. 3-14 (2020) 